\title{
Long-term outcomes of percutaneous closure of patent ductus arteriosus accompanied with unilateral absence of pulmonary artery
}

zhiyuan wang ${ }^{1}$, baojing guo ${ }^{1}$, xiaofang wang $^{1}$, yanyan xiao ${ }^{1}$, zhenyu $^{1}{ }^{1}$, yongmei liang ${ }^{1}$, and mei jin ${ }^{1}$

${ }^{1}$ Capital Medical University Affiliated Anzhen Hospital

November 4, 2020

\begin{abstract}
Objective: This study aimed to evaluate the long-term outcome of patients with PDA associated with UAPA. Methods: Patients diagnosed with PDA associated with UAPA were retrospectively enrolled from January 2005 to June 2019 . Clinical data, treatment and follow-up information were evaluated. Results: 11 patients (5 males and 6 females) were diagnosed with PDA associated with UAPA. Percutaneous closure was conducted in 9 patients successfully. The median age was 37 months. The mean diameter of the PDA and occluders were $5.3 \pm 1.8 \mathrm{~mm}$ (range 2-8.1 mm), 11.5 $\pm 3.9 \mathrm{~mm}$ (4-16 mm) respectively. The median in 5 patients with the pulmonary: systemic flow ratio (Qp:Qs) was 1.41(1.28-8.7) and total lung resistance was 12 wood (1.8-13.6) . The mean systolic pulmonary artery pressure was $68.3 \pm 19.1 \mathrm{mmHg}(42-105 \mathrm{mmHg})$. In 5 patients with pre- and post-procedure catheter data, the systolic pulmonary arterial pressure decreased significantly after closure $77.0+-20.2 \mathrm{v} 58.8+-$ $17.5 \mathrm{mmHg}(\mathrm{p}=0.024)$, and so was the mean pulmonary arterial pressure 58.2+-14.6 v 39.0+-14.1 $\mathrm{mmHg}(\mathrm{p}=0.18)$. The pulmonary artery pressure and heart size gradually decreased to normal in 8 patients, and the quality of life was significantly improved. The ratio of lung to systemic circulation pressure in all these patients was less than 0.75. Conclusions: In appropriate patients with PDA associated with UAPA, transcatheter closure of PDA has the potential to improve the pulmonary artery hypertension. The ratio of lung to systemic circulation pressure less than 0.75 may be important reference index for predicting whether the pulmonary artery pressure could be reduced to normal after occlusion.
\end{abstract}

\section{Hosted file}

unilateral absence of pulmonary artery.pdf available at https://authorea.com/users/373131/ articles/490907-long-term-outcomes-of-percutaneous-closure-of-patent-ductus-arteriosusaccompanied-with-unilateral-absence-of-pulmonary-artery 